\section{Limited Mobility: The UK Case}

Simon Robins considers the example of the UK in attempting to understand why job mobility within the European Union is low in spite of the generally positive attitude of young people and the energy devoted to creating the single market.

The European single market is in principle a free market in labour as well as goods, offering physicists from European Union (EU) Member States the opportunity to work in any state of the Union. In practice the situation is somewhat more complex. Here we have looked at the particular experience of British physics graduates as an example of how this mobility is being exercised, and what barriers to mobility remain.

Surprisingly given the energy devoted to creating the single market, data recording the mobility of Europeans within the Union is both scarce and poorly coordinated between Member States. This makes definitive statements and comparisons difficult. However, some conclusions can be drawn from the data that are available with regard to United Kingdom graduates. Fewer than $1 \%$ of the $2300-2500$ UK graduates obtaining their first degree (B.Sc.) in physics each year go to overseas employment as their first destination [based on an analysis of the Universities Statistical Record by the Association of Graduate Careers Advisory Service]. This fraction excludes overseas students, who may be returning to their home country. Whilst the data ignore those graduates who ultimately find employment abroad some time after graduation, the analysis suggests that the number of UK physicists working in other European states is small.

\section{Expectations Differ}

There are certainly many different reasons for this low level of traffic, not least the possibility that many British graduates may not want to work abroad (although young Britons tend to be much more positive about Europe than the majority of their politicians). However, for Europhile students wishing to work in the EU there are several barriers to overcome. The most immediate of these is to interest an overseas employer, and here they are limited by what a British graduate can offer compared to a local (or other Euro-

Simon Robins is a research associate at Queen Mary and Westfield College, University of London, working in experimental particle physics. He took a first degree at Liverpool University and his Ph.D. at Queen Mary and Westfield College. pean) graduate. The most glaring difference between UK graduates and the typical European graduate is in age. The British first degree has traditionally taken three (but increasingly four) years, and so British graduates enter the job market aged 21 or 22 years, younger and with less experience than their continental counterparts. They do however have the advantage of being able to gain more industrial or post-graduate experience at an equivalent age than, say, their French or German contemporaries. Indeed, the British graduate with a higher degree appears to be extremely attractive to the European employer. The British education system traditionally produces graduates who may well expect to work in an area unrelated to their degree course; this lack of vocational direction is in contrast to most European courses. Generally a European employer will be struck by the youth and relative inexperience of many British graduates.

A UK graduate is also far less likely than many to have a second language, and this may clearly be a barrier to overseas employment. Of course, UK graduates also have English as their mother tongue, which may be a considerable bonus in many situations. Overall, however, the problem faced by UK graduates in attracting the attention of overseas employers seems to be due not to their being of insufficient calibre but rather to a discrepancy between the employer's expectation and what the UK graduate can offer.

\section{Resources Available}

Resources to assist UK graduates in attempts to work abroad do exist. The government's Cabinet Office has a European Staffing Unit that aims to increase the UK presence on the staff of the Commission and some scientists are employed through this route. Generally, however, the government shows little enthusiasm for providing incentives to graduates to work abroad. The excellent careers services (almost unique in the EU) offered in UK universities provide expert advice to stubegun to offer access to the European Employment Services (EurES) vacancies dents and graduates, and have recently database in some institutes. The EU funds several schemes that exist explicitly to increase mobility within Europe for young people. The Leonardo programme provides vocational training, and Socrates (incorporating the successful Erasmus programme) offers the opportunity to study abroad - clearly an experience that makes working abroad much more likely. The Stagiaire scheme offers possibilities of in-service training within the European Commission, and the Training and Mobility of Researchers (TMR) programme provides funds for the mobility of researchers, usually those already holding a Ph.D.

The Internet also provides a direct route to jobs abroad. As physicists have increasingly worked with the technology of the Internet, so too have physics job seekers and advertisers. This is a potential resource that necessarily fails to recognize national frontiers. Several organizations (among them the EPS) provide Web pages offering access to lists of physics job vacancies. This is a tool that is likely to become increasingly important as a source of vacancy information overseas.

In summary, it is clear that few UK physics graduates are gaining posts abroad despite the promise of a Europe without frontiers. This appears to be due largely to perceived incompatibilities between the graduates UK universities are producing and the expectations of the typical continental employer, although the differences between UK and other European graduates do not seem to be profound. The collection of comprehensive and comparable statistics throughout Europe would enable firmer conclusions to be drawn about the reality, problems and possibilities of the free transfer of physicists within the EU and beyond.

The number of UK graduates in all disciplines who obtained their first position or undertook up a postgraduate course in continental Europe. It should be noted that as many as $40 \%$ are teaching English. Of the about 2300 physics graduates in 1994 , only about $1 \%$ found employment outside the UK.

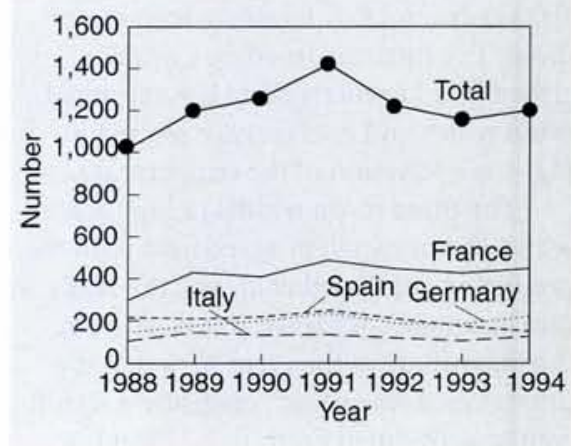

